\section{BMJ Open Respiratory Research}

\title{
Downregulation of epithelial sodium channel (ENaC) activity in human airway epithelia after low temperature incubation
}

\author{
Sangya Yadav, ${ }^{1}$ Ciaran A Shaughnessy, ${ }^{1}$ Pamela L Zeitlin, ${ }^{1,2}$ \\ Preston E Bratcher (1) 1,2
}

To cite: Yadav S, Shaughnessy CA, Zeitlin PL, et al. Downregulation of epithelial sodium channel $(\mathrm{ENaC})$ activity in human airway epithelia after low temperature incubation. BMJ Open Resp Res 2021;8:e000861. doi:10.1136/ bmjresp-2020-000861

SY and CAS contributed equally.

Received 16 December 2020 Revised 28 January 2021 Accepted 13 February 2021
A) Check for updates

(C) Author(s) (or their employer(s)) 2021. Re-use permitted under CC BY-NC. No commercial re-use. See rights and permissions. Published by BMJ.

${ }^{1}$ Department of Pediatrics, National Jewish Health, Denver, Colorado, USA ${ }^{2}$ Department of Pediatrics, University of Colorado Anschutz Medical Campus, Aurora, Colorado, USA

Correspondence to Dr Preston E Bratcher; BratcherP@NJHealth.org

\section{ABSTRACT}

Introduction The incubation of airway epithelia cells at low temperatures is a common in vitro experimental approach used in the field of cystic fibrosis (CF) research to thermo-stabilise F508del-CFTR and increase its functional expression. Given that the airway epithelium includes numerous ion transporters other than CFTR, we hypothesised that there was an impact of low temperature incubation on CFTR-independent ionoregulatory mechanisms in airway epithelia derived from individuals with and without $\mathrm{CF}$.

Methods After differentiation at the air-liquid interface, nasal epithelia were incubated at either $37^{\circ} \mathrm{C}$ or $29^{\circ} \mathrm{C}$ (low temperature) for 48 hours prior to analysis in an Ussing chamber.

Results While F508del-CFTR activity was increased after low temperature incubation, activity of CFTR in non-CF epithelia was unchanged. Importantly, cultures incubated at $29^{\circ} \mathrm{C}$ demonstrated decreased transepithelial potential difference (TEPD) and short-circuit currents (ISC) at baseline. The predominant factor contributing to the reduced baseline TEPD and Isc in $29^{\circ} \mathrm{C}$ cultures was the reduced activity of the epithelial sodium channel (ENaC), evidenced by a reduced responsiveness to amiloride. This effect was observed in cells derived from both non-CF and CF donors.

Discussion Significant transcriptional downregulation of ENaC subunits $\beta$ and $\gamma$ were observed, which may partially explain the decreased ENaC activity. We speculate that low temperature incubation may be a useful experimental paradigm to reduce $\mathrm{ENaC}$ activity in in vitro epithelial cultures.

\section{INTRODUCTION}

The conducting and respiratory airway epithelia of the nose, mouth, trachea, bronchi and alveoli process inhaled air for gas exchange while protecting from potentially harmful inhaled particles and pathogens. Key to both the respiratory and protective functions of airway epithelia is maintaining hydromineral balance of the periciliary fluid compartment of the airway surface liquid (ASL), a thin layer of fluid that serves to trap

\section{Key messages}

Given the wide use of low temperature incubation of airway epithelial cells to experimentally correct mutant cystic fibrosis transmembrane conductance regulator (CFTR), the current investigation sought to evaluate the impact of low temperature on the activities of other epithelial ion transporters of the airway epithelium.

- It appears that low temperature treatment downregulates the epithelial sodium channel $(\mathrm{ENaC})$ activity and expression through a mechanism that is not dependent on CFTR, and that the reduced ENaC function at low temperature has a direct impact on baseline transepithelial membrane potential.

- Future studies seeking to use low temperature incubation to experimentally correct mutant CFTR should consider the impact low temperature incubation may have on other ion transporters as well as on epithelial function more broadly, including impacts on transepithelial potential difference, airway surface hydration and mucociliary transport.

and flush out debris and pathogens. ${ }^{1}$ ASL hydration is maintained by the osmotic movement of water driven by ion transport across the epithelium. Three of the most prominent ion transporters on the apical side of the airway epithelium are: (i) epithelial $\mathrm{Na}^{+}$ channel (ENaC), which transports $\mathrm{Na}^{+}$from the ASL into the cell; (ii) cystic fibrosis transmembrane conductance regulator (CFTR), a $\mathrm{Cl}^{-}$channel that transports $\mathrm{Cl}^{-}$out of the cell to the ASL and (iii) $\mathrm{Ca}^{2+}$-activated $\mathrm{Cl}^{-}$channels (CaCCs), which also transport $\mathrm{Cl}^{-}$out to the ASL. ${ }^{2}$

Cystic fibrosis (CF) is an autosomal recessive disease caused by mutations in the CFTR gene resulting in a deterioration of the ASL and an overaccumulation of mucus in the airways leading to respiratory dysfunction and chronic lung disease. ${ }^{3}$ The most common CFTR mutation, F508del, ${ }^{4}$ results 
in misfolding and retention of the mutant CFTR protein in the endoplasmic reticulum, leading to the premature degradation of F508del-CFTR by proteasomes and an inadequate amount of F508del-CFTR at the cell surface. ${ }^{56}$ The misfolding of F508del-CFTR is temperature-sensitive and can be partially rescued by incubation at low temperature. ${ }^{7-9}$ Thus, a widely used experimental methodology to correct F508del-CFTR folding in vitro is to thermo-stabilise F508del-CFTR using low temperature incubation (at $\sim 27^{\circ} \mathrm{C}-29^{\circ} \mathrm{C}$ rather than $37^{\circ} \mathrm{C}$ ) of cells harbouring F508del-CFTR. Low temperature correction of F508del-CFTR is also an important experimental tool in translational research on $\mathrm{CF}$ as it has served as a positive control treatment in studies screening for and investigating the efficacy of novel pharmacological correctors of F508del-CFTR. ${ }^{10-12}$

In $\mathrm{CF}$ research, ENaC has also been widely investigated for its abundance on the airway epithelium and its prominent contribution to ion and fluid homeostasis on the airway surface. ${ }^{2}$ The balance of ENaC-mediated ion absorption and CFTR-mediated ion secretion largely determines proper ASL homeostasis. ${ }^{13}$ CFTR and ENaC interact on the apical membrane of the airway epithelium, ${ }^{14}$ both through direct and indirect means. In non-CF epithelia, membrane-expressed CFTR directly interacts with and downregulates the function of ENaC. Likewise, $\mathrm{ENaC}$ activity is increased in $\mathrm{CF}$ epithelia, which have low membrane expression of CFTR. ${ }^{14}$ This relationship between ENaC and CFTR is so crucial that it has been suggested that $\mathrm{ENaC}$ should be a target in treating $\mathrm{CF}^{1516}$ For example, it has been posited that pharmacologically reduced ENaC activity on the apical surface could lead to increased periciliary fluid and enhanced lung function in CF airways. ${ }^{13}$ This paradigm is perhaps most conspicuous in murine models of $\mathrm{CF}$, of which models overexpressing $\mathrm{ENaC}$ in the airway more closely exhibit pulmonary symptoms of $\mathrm{CF}$ than $\mathrm{Cftr}^{-/-}$models. ${ }^{17}$

Given the use of low temperature incubation experiments to investigate F508del-CFTR and airway epithelial ion transport, the current study sought to evaluate the impact of low temperature on the activities of other epithelial ion transporters of the airway epithelium. In this study, we exposed patient-derived non-CF and CF (F508del homozygous) nasal epithelial cells to low temperature. We performed electrophysiological analyses to examine the effect of low temperature incubation on the activities of amiloride-sensitive $\mathrm{ENaC}$, forskolinactivated CFTR and ATP-responsive CaCCs. This report provides further characterisation of the impact of low temperature on the electrophysiological properties and ion channel functions of cultured airway epithelia.

\section{MATERIALS AND METHODS}

Primary human nasal epithelial cell expansion and maintenance

Primary nasal cells were obtained from three to four individuals with and without CF by nasal brushing and cultured as previously described. ${ }^{18-21}$ Cells were expanded on irradiated National Institutes of Health (NIH)-registered 3T3 feeder layers with F-media (73\% complete Dulbecco's Modified Eagle's Medium (DMEM) (89\% DMEM, 9\% fetal bovine serum, 1\% L-glutamine, $1 \%$ penicillin/streptomycin), $0.1 \%$ hydrocortisone/ EGF mix, $0.00086 \%$ cholera toxin, $1.6 \%$ adenine, $0.1 \%$ insulin, 25\% Ham's F-12) containing $10 \mu \mathrm{M}$ Y-27632 Rho kinase inhibitor. For differentiation at air-liquid interface (ALI), expanded cells were seeded on type 1 bovine collagen-coated $(3 \mathrm{mg} / \mathrm{mL}$ ) cell culture permeable polyester transwell inserts (Corning) at a density of 250000 cells $/ \mathrm{cm}^{2}$ in PneumaCult-Ex Plus (STEMCELL Technologies). Apical media was removed and basal media was replaced by PneumaCult-ALI media (STEMCELL Technologies) after 2 days of expansion. The basal media was changed every 2-3 days with fresh PneumaCult-ALI media. Cells were well-differentiated and analysed after 21-28 days at ALI. For low temperature incubation, cells were either held at $37^{\circ} \mathrm{C}$ (control) or transferred to $29^{\circ} \mathrm{C}$ for 48 hours prior to analysis in the Ussing chamber (four replicates per group for each individual donor).

\section{Electrophysiological measurement by Ussing chamber}

Electrophysiological measurements were performed in an Ussing chamber (Physiological Instruments) under open-circuit conditions with continuous measurement of transepithelial potential difference (TEPD). Monolayers were intermittently voltage-clamped to $0 \mathrm{mV}$ for measurement of short-circuit current (Isc). During periods of short-circuiting, epithelia were pulsed $(200 \mathrm{~ms}$ of $\pm 5 \mathrm{mV}$ ) and measurements of transepithelial electrical resistance (TEER) were obtained. Cells were placed between apical and basolateral compartments filled with Ringer's solution (120 mM NaCl, $10 \mathrm{mM}$ D-glucose, 3.3 $\mathrm{mM} \mathrm{KH}_{2} \mathrm{PO}_{4}, 0.83 \mathrm{mM} \mathrm{K} \mathrm{HPO}_{4}, 1.2 \mathrm{mM} \mathrm{MgCl}, 1.2 \mathrm{mM}$ $\mathrm{CaCl}_{2}$, saturated with $95 \% \mathrm{O}_{2} / 5 \% \mathrm{CO}_{2}, \mathrm{pH} 7.4$ at $37^{\circ} \mathrm{C}$ ). After mounting in the Ussing chamber, solutions were continuously gassed with $5 \% \mathrm{CO}_{2}$ and $95 \% \mathrm{O}_{2}$. Acute treatments of the monolayers in the Ussing chamber consisted of apical $100 \mu \mathrm{M}$ amiloride (Alfa Aesar), apical/basal $20 \mu \mathrm{M}$ forskolin (Fsk; Tocris)/100 $\mu \mathrm{M}$ 3-isobutyl-1-methylxanthine (IBMX; Sigma), apical $1 \mu \mathrm{M}$ VX-770 (Selleck Chemicals), apical $10 \mu \mathrm{M}$ CFTR(inh)-172 (CFTR Chemical Compound Distribution Program) and apical $100 \mu \mathrm{M}$ ATP (Sigma). For non-CF cultures, CFTR was potentiated with VX-770 then activated by Fsk/IBMX. For CF cultures, CFTR was activated by Fsk/IBMX then potentiated with VX-770. After Ussing chamber analysis, monolayers were immediately frozen and stored at $-80^{\circ} \mathrm{C}$.

\section{Gene expression analysis}

Total RNA was isolated from frozen cells using the TRI-zol method following manufacturer's protocol (Molecular Research Center) and quantified and assessed for purity using a NanoDrop spectrophotometer (ND-1000; NanoDrop Technologies). First-strand complementary DNA (cDNA) was synthesised using a reverse transcription kit 
following the manufacturer's protocol (M-MLV Reverse Transcriptase; Invitrogen). Real-time quantitative PCR (RT-qPCR) was performed using a StepOnePlus system (Applied Biosystems) and carried out in $10 \mu \mathrm{L}$ reactions containing $10 \mathrm{ng}$ cDNA, $150 \mathrm{nM}$ forward and reverse primers and 1X SYBRselect master mix, following the manufacturer's protocol (ThermoFisher). The thermal profile of the reactions was $2 \mathrm{~min}$ at $50^{\circ} \mathrm{C}, 2 \mathrm{~min}$ at $95^{\circ} \mathrm{C}$ (holding and activation), 40 cycles of $15 \mathrm{~s}$ at $95^{\circ} \mathrm{C}, 30 \mathrm{~min}$ at $60^{\circ} \mathrm{C}, 30 \mathrm{~s}$ at $72^{\circ} \mathrm{C}$ (cycling), then finally a ramp from $60^{\circ} \mathrm{C}$ to $95^{\circ} \mathrm{C}$ (melt curve analysis) was used to confirm a single product in each reaction. Relative mRNA expression of SCNN1A, SCNN1B and SCNN1G (the genes corresponding to $\alpha, \beta$ and $\gamma$ subunits of $\mathrm{ENaC}$, respectively) was calculated using the comparative method $\left(2^{-\Delta \Delta \mathrm{CT}}\right)$ using $\alpha$-tubulin $(A T U B A 1 A)$ as a reference gene. Nucleotide sequences of primer pairs used for analysis were as follows: SCNN1A forward, 5'-AGGGGAACAAGCGTGAGGA-3'; SCNN1A reverse, 5'-GGTGGAACTCGATCAGGGC-3'; $S C N N 1 B$ forward, 5'-CCCGGCTACACGTACAAGG-3'; $S C N N 1 B$ reverse, 5'-CCCTCACAGATGATGCGCTT-3'; SCNN1G forward, 5'-GCACCCGGAGAG AAGATCAAA-3'; $S C N N 1 G$ reverse, 5'-TACCACCGCATC AGCTCTTTA-3'.

\section{Western blot analysis}

Frozen monolayers were washed with ice-cold phosphatebuffered saline and lysed with 1X Laemmli buffer. Equal amounts of protein $(20 \mu \mathrm{g})$ were loaded for SDS-PAGE, then transferred on to nitrocellulose membrane (GE-Amersham Biosciences). Blots were subsequently blocked with 5\% Blotto (non-fat dry milk; Sigma) in tris-buffered saline with $0.1 \%$ Tween-20 (TBS-T) for 1 hour at room temperature (RT), followed by overnight incubation with primary antibodies: ENaC (1:1000 dilution; Invitrogen, Cat. No. 920A); actin (1:3000 dilution; Cell Signaling Technology, Cat. No. 12262). After primary incubation, blots were washed with TBS-T then incubated in HRPconjugated secondary antibodies (1:3000 dilution; Cell Signaling Technology, Cat. No. 7074) for 1 hour at RT, then washed again before chemiluminescent detection (ECL western blotting substrate; Pierce, Cat. No. 32106). $\mathrm{ENaC} \alpha$-subunit band densities were normalised to $\beta$-actin and quantified using Image J software (NIH).

\section{Calculations and statistical analysis}

To control for donor-to-donor variation, data were normalised to the donor-matched $37^{\circ} \mathrm{C}$ control. Statistical analyses were carried out on normalised replicates from each donor $(n=16-34$ replicates from three to four donors) by either one-way or two-way analysis of variance with Tukey's multiple comparisons test, unpaired t-test or linear regression as described in figure legends. All data are presented as mean \pm SD. Figure assembly and all statistical analyses were completed in Prism V.6.0 (GraphPad Software).
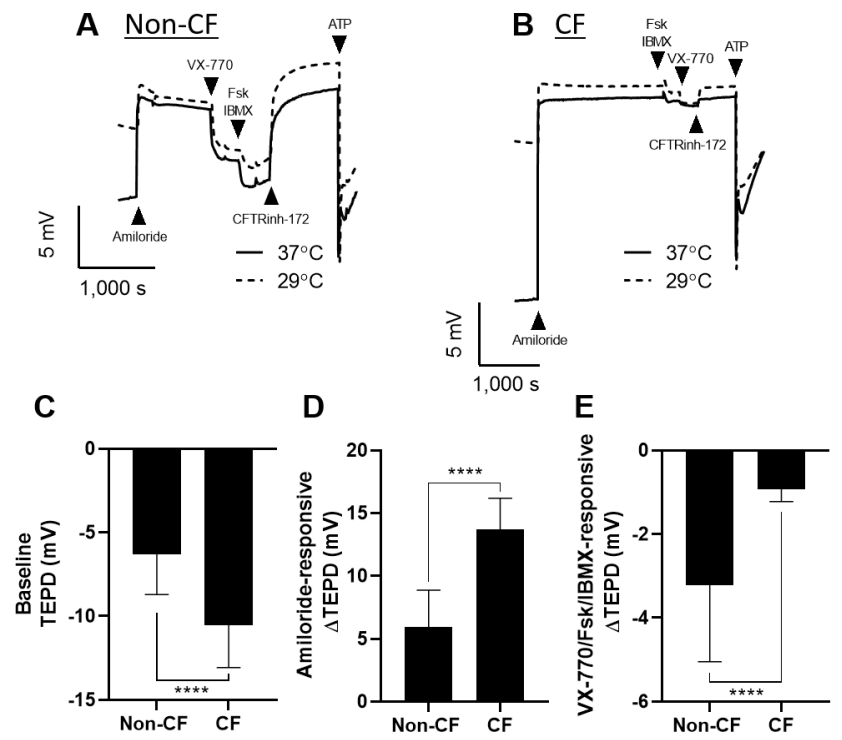

Figure 1 Electrophysiological properties of nasal airway epithelia. (A) Traces of transepithelial potential difference (TEPD) across non-cystic fibrosis (non-CF) (A) and CF (F508del/F508del) (B) primary nasal epithelial cells after 48 hours incubation at low temperature $\left(29^{\circ} \mathrm{C}\right)$ and normal temperature $\left(37^{\circ} \mathrm{C}\right)$ were obtained by analysis in an Ussing chamber. Baseline TEPD (C), amiloride-responsive $\triangle T E P D$ (D) and VX-770/Fsk/IBMX-mediated $\triangle \mathrm{TEPD}(\mathrm{E})$ in non-CF and CF epithelia were quantified. Data are presented as mean $\pm S D(n=16-34$ replicates, from three individual donors for each group). Brackets and asterisks indicate significant differences (t-test; $\left.{ }^{* \star * *} p<0.0001\right)$.

\section{Patient and public involvement}

Patients or the public were not involved in the design, or conduct, or reporting, or dissemination plans of our research.

\section{RESULTS}

Non-CF and CF primary nasal epithelial cell cultures formed visibly ciliated and electrically tight monolayers, ranging $93-358 \Omega / \mathrm{cm}^{2}$ at baseline. All monolayers exhibited an immediate response and subsequent stabilisation after exposure to the test compounds amiloride, VX-770, Fsk/IBMX, CFTR(inh)-172 and ATP (figure 1A,B). Non-CF and CF epithelia had significantly different baseline TEPD (non-CF: $-6.3 \pm 2.3 \mathrm{mV}$; CF: $-10.5 \pm 2.5 \mathrm{mV}$ ), amiloride-responsive $\triangle \mathrm{TEPD}$ (non-CF: $5.9 \pm 2.8 \mathrm{mV}$; CF: $13.6 \pm 2.5 \mathrm{mV}$ ) and VX-770/Fsk/IBMX-responsive $\triangle \mathrm{TEPD}$ (non-CF: $-3.8 \pm 1.8 \mathrm{mV}$; $\mathrm{CF}:-0.92 \pm 0.29 \mathrm{mV}$ ) (figure $1 \mathrm{C}-\mathrm{E}$ ).

We first sought to compare the effects of low temperature $\left(29^{\circ} \mathrm{C}\right.$ ) incubation on baseline values (prior to administration of test compounds) for TEPD, Isc and TEER between non-CF and CF nasal epithelial cell cultures. We observed a significant reduction in baseline TEPD and Isc after $29^{\circ} \mathrm{C}$ incubation compared with the control temperature $\left(37^{\circ} \mathrm{C}\right)$, and this effect was consistent in both non-CF and $\mathrm{CF}$ epithelial cell cultures (figure 2A,B). Low temperature-mediated decreases in baseline TEPD and Isc were greater in CF cells (TEPD 

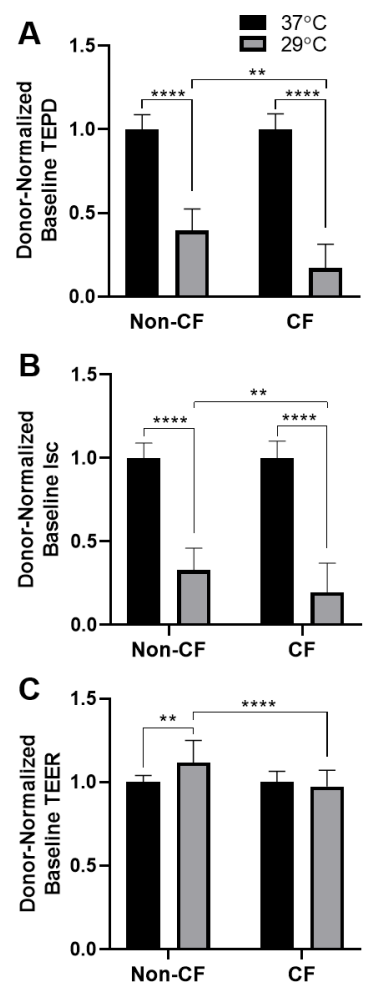

Figure 2 Baseline transepithelial properties. Effects of 48 hours treatment with normal $\left(37^{\circ} \mathrm{C}\right)$ and low temperature $\left(29^{\circ} \mathrm{C}\right)$ on baseline transepithelial potential difference (TEPD) (A), short-circuit currents (ISC) (B) and transepithelial electrical resistance (TEER) (C) across non-cystic fibrosis (non-CF) and CF (F508del/F508del) primary nasal epithelial cells were quantified. Values were normalised to donormatched $37^{\circ} \mathrm{C}$ values. Data are presented as mean \pm SD ( $n=16-34$ replicates, from three individual non-CF and three individual CF donors). Brackets and asterisks indicate significant differences (two-way analysis of variance; Tukey's post hoc; ${ }^{* \star} \mathrm{p}<0.01 ;{ }^{* \star \star \star} \mathrm{p}<0.0001$ ).

was reduced $82 \% \pm 14 \%$; Isc was reduced in $80 \% \pm 17 \%$ ) compared with non-CF cells (TEPD was reduced $60 \% \pm 13 \%$; Isc was reduced in $67 \% \pm 13 \%$ ). Low temperature incubation had only modest influences on TEER, slightly increasing TEER in non-CF cells and having no effect in CF cells (figure 2C).

The acute application of amiloride, a potent inhibitor of ENaC, had large and temperature-dependent effects on TEPD and Isc across both non-CF and CF epithelia. The magnitude of amiloride-responsive $\triangle \mathrm{TEPD}$ and $\Delta$ Isc were significantly reduced at $29^{\circ} \mathrm{C}$ compared with $37^{\circ} \mathrm{C}$ control epithelia (figure 3A,B). In non-CF epithelia at $29^{\circ} \mathrm{C}$, amiloride-responsive $\triangle$ TEPD and $\triangle$ Isc were decreased to $47 \% \pm 22 \%$ and $59 \% \pm 21 \%$, respectively, compared with $37^{\circ} \mathrm{C}$ controls. In $\mathrm{CF}$ epithelia at $29^{\circ} \mathrm{C}$, amiloride-responsive $\triangle \mathrm{TEPD}$ and $\triangle \mathrm{Isc}$ were decreased to $62 \% \pm 9 \%$ and $59 \% \pm 13 \%$, respectively. In non-CF epithelia, CFTR activation by VX-770 and Fsk/IBMX was not different between $29^{\circ} \mathrm{C}$ and $37^{\circ} \mathrm{C}$ treatments (figure 3C,D). However, in CF epithelia, CFTR activation by Fsk/IBMX and VX-770 resulted in a significant increase in $\triangle \mathrm{TEPD}$ at $29^{\circ} \mathrm{C}$ compared with the $37^{\circ} \mathrm{C}$
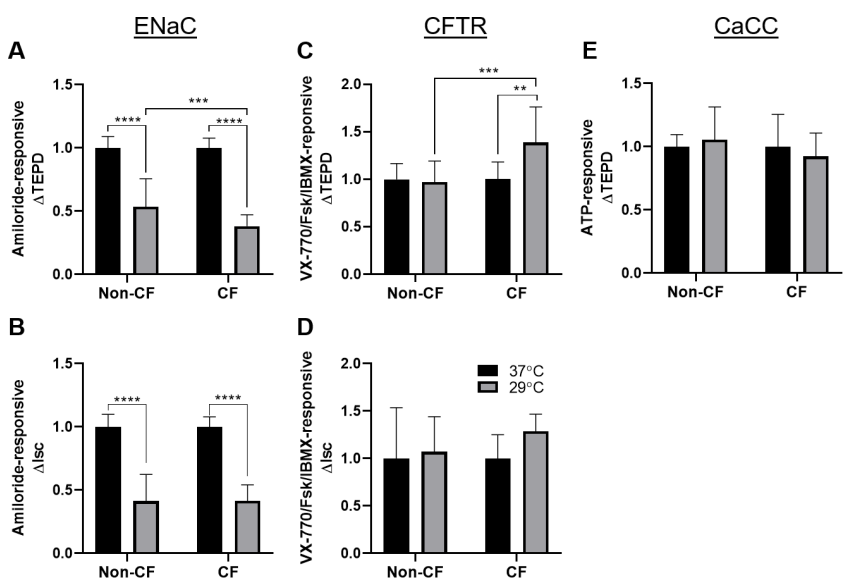

Figure 3 Transepithelial response to amiloride, cystic fibrosis transmembrane conductance regulator (CFTR) activation and ATP stimulation. Treatment with normal $\left(37^{\circ} \mathrm{C}\right)$ and low temperature $\left(29^{\circ} \mathrm{C}\right)$ for 48 hours affects amiloride $(100 \mu \mathrm{M})$-sensitive $\Delta$ transepithelial potential difference (TEPD) (A) and $\triangle$ short-circuit currents (ISc) (B) in non-cystic fibrosis (non-CF) and CF (F508del/F508del) epithelia. CFTR-mediated changes in TEPD (C) and Isc (D) responded to low temperature in CF (F508del/F508del) but not non-CF primary nasal epithelial cells. Values for CFTR activation represent total changes in response to $\mathrm{VX}-770$ and Fsk/IBMX application. ATP-responsive $\triangle T E P D(E)$ in non-CF and CF primary nasal epithelial cells remained unchanged. Data are presented as mean $\pm S D(n=16-34$ replicates, from three individual non-CF and three individual CF donors). Brackets and asterisks indicate significant differences (two-way analysis of variance; Tukey's post hoc; $\left.{ }^{\star \star} \mathrm{p}<0.01 ;{ }^{\star \star \star} \mathrm{p}<0.001 ;{ }^{\star \star \star *} \mathrm{p}<0.0001\right)$.

control (figure 3C). Low temperature incubation had no detectable effect on CFTR-activated $\triangle \mathrm{Isc}$ in either non-CF or CF epithelia (figure 3D). It is important to note that the effect of temperature correction on F508del-CFTR is very moderate when assayed under symmetrical $\mathrm{Cl}^{-}$ conditions; more dramatic increases in F508del-CFTR activity after low-temperature incubation are observed in the presence of a $\mathrm{Cl}^{-}$gradient. ${ }^{18}$ Although the acute addition of ATP elicited a strong response in $\mathrm{Cl}^{-}$conductance in both non-CF and CF epithelia (figure 1), no significant effect of low temperature incubation on the ATP response was detected in either non-CF or CF epithelia (figure 3E).

For non-CF and CF epithelia at both incubation temperatures, baseline TEPD was significantly correlated with $\mathrm{ENaC}$-mediated $\triangle \mathrm{TEPD}$ (figure $4 \mathrm{~A}$ ). The results of linear regression were as follows: $37^{\circ} \mathrm{C}$ non-CF: $m=-0.7796$, $r^{2}=0.9191, \mathrm{p}<0.0001 ; 29^{\circ} \mathrm{C}$ non-CF $: m=-0.5133, r^{2}=0.9441$, $\mathrm{p}<0.0001 ; 37^{\circ} \mathrm{C} \mathrm{CF}: m=-0.9911, r^{2}=0.9535, \mathrm{p}<0.0001 ; 29^{\circ} \mathrm{C}$ CF: $m=-1.060, r^{2}=0.8251, p<0.0001$. The influence of ENaC on baseline TEPD was greater in CF epithelia than in non-CF epithelia; the slopes of the lines were significantly different $(\mathrm{p}<0.0001)$. In non-CF epithelia, the influence of ENaC on baseline TEPD was greater at $37^{\circ} \mathrm{C}$ compared with $29^{\circ} \mathrm{C}(\mathrm{p}=0.0007)$. Baseline TEPD was only significantly associated with CFTR activity in non-CF cells 

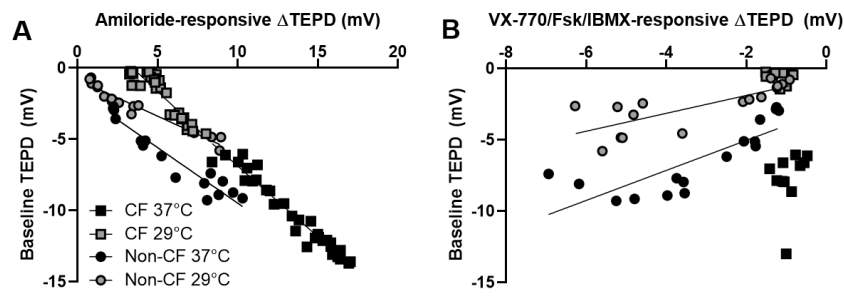

C

$$
\text { D }
$$
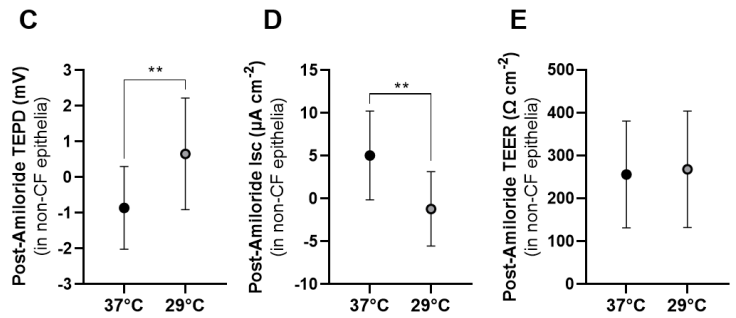

Figure 4 Relationship between ion transporter activities and baseline epithelial properties. The effect of 48 hours treatment with normal $\left(37^{\circ} \mathrm{C}\right)$ and low $\left(29^{\circ} \mathrm{C}\right)$ temperature on transepithelial potential difference (TEPD) across noncystic fibrosis (non-CF) and CF (F508del/F508del) primary nasal epithelial cells was analysed. Correlations between baseline TEPD and amiloride $(100 \mu \mathrm{M})$-sensitive $\triangle$ TEPD (A) or $\triangle T E P D$ from cystic fibrosis transmembrane conductance regulator (CFTR) activation (B) are presented. Values for CFTR activation represent total changes in response to VX-770 $(1 \mu \mathrm{M})$ and Fsk/IBMX $(20 \mu \mathrm{M} / 100 \mu \mathrm{M})$ application. (C-E) Absolute values for TEPD, short-circuit currents (Isc) and transepithelial electrical resistance (TEER) in non-CF epithelial cells at normal $\left(37^{\circ} \mathrm{C}\right)$ and low $\left(29^{\circ} \mathrm{C}\right)$ temperature after the acute addition of amiloride were quantified. Data in panels $A$ and $B$ are presented as individual replicates ( $n=12-34$ replicates, from three individual non-CF and three individual CF donors) and analysed using linear regression. Data in panels C-E are presented as mean \pm SD. Brackets and asterisks indicate significant differences (t-test; $\left.{ }^{* *} \mathrm{p}<0.01\right)$.

(figure $4 \mathrm{~B}$ ): $37^{\circ} \mathrm{C}$ non-CF: $m=1.053, r^{2}=0.6530, \mathrm{p}=0.0002$; $29^{\circ} \mathrm{C}$ non-CF: $m=0.6273, r^{2}=0.5941, \mathrm{p}=0.0005$. After the addition of amiloride in non-CF epithelia, significant differences in TEPD and Isc (but not TEER) remained between $37^{\circ} \mathrm{C}$ and $29^{\circ} \mathrm{C}$ treatments (figure $4 \mathrm{C}-\mathrm{E}$ ).

Lastly, we hypothesised that the effect of low temperature incubation on ENaCactivity was explained by reduced ENaC expression. RT-qPCR analysis (figure 5A-C) revealed that $S C N N 1 B$ and $S C N N 1 G$ transcript expression were significantly reduced at $29^{\circ} \mathrm{C}$ compared with $37^{\circ} \mathrm{C}$ (over $50 \%$ reduction each). This effect of temperature was observed in both non-CF and CF epithelia. Interestingly, SCNN1A transcript expression was not significantly downregulated at $29^{\circ} \mathrm{C}$. Further analysis of SCNN1A by western blot analysis indicated that low temperature incubation resulted in a modest $(\sim 25 \%)$ but significant decrease in levels of $\mathrm{ENaC} \alpha$-subunit-the $97 \mathrm{kDa}$ band corresponds to the glycosylated, thus active, form of ENaC $\alpha$-subunit. ${ }^{22} 23$ This downregulatory effect on glycosylated $\mathrm{ENaC} \alpha$-subunit protein expression was observed in both CF and non-CF cells (figure 5D,E).
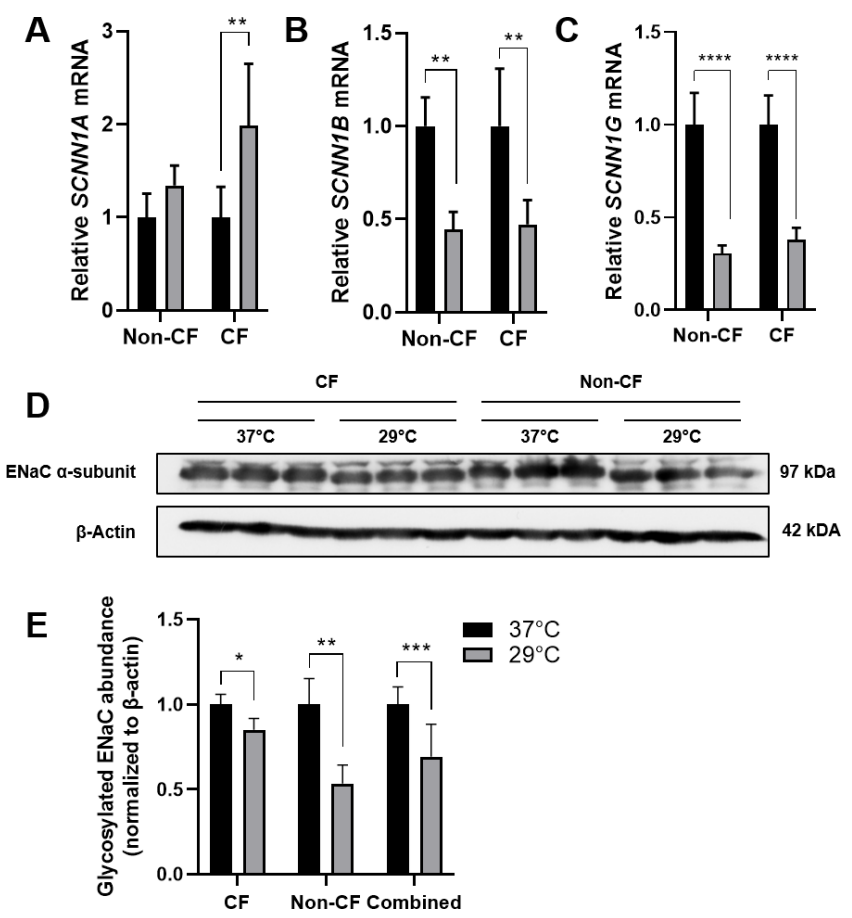

Figure 5 Transcript and protein expression of epithelial sodium channel (ENaC) subunits. (A-C) Transcript expression of ENaC subunits $\alpha, \beta$ and $\gamma$ (SCNN1A, $S C N N 1 B$ and SCNN1G, respectively) are presented. Transcript expression data were calculated using the comparative method $\left(2^{-\Delta \Delta C T}\right)$ with $\alpha$-tubulin (ATUBA1A) serving as the reference gene. Transcript levels are presented as relative to $37^{\circ} \mathrm{C}$ (set to 1 ) ( $\mathrm{n}=4$ replicates). (D) Western blot analyses demonstrate the expression of ENaC $\alpha$-subunit in cystic fibrosis (CF) and non-CF after 48 hours treatment with normal $\left(37^{\circ} \mathrm{C}\right)$ and low temperature $\left(29^{\circ} \mathrm{C}\right)$. $\beta$-Actin was used as a loading control. (B) Quantification of ENaC protein band densities are presented $(n=5-6$ replicates from two donors). Data are presented as mean \pm SD. Asterisks indicate significant differences (unpaired t-test; ${ }^{*} p<0.05 ;{ }^{* \star} p<0.01,{ }^{\star \star \star \star} p<0.0001$ ).

\section{DISCUSSION}

The balance between ENaC and CFTR on the airway epithelium is critical in maintaining airway surface ion and fluid homeostasis. In the present study, we demonstrated that low temperature treatment of airway epithelial cells in vitro, which is an experimental approach often used to modulate F508del-CFTR, also reduced $\mathrm{ENaC}$ activity in both non-CF and $\mathrm{CF}$ airway epithelia. We further demonstrated that $\mathrm{ENaC}$ activity is highly correlated to baseline TEPD, implying that $\mathrm{ENaC}$ is critical in producing the lumen-negative TEPD present in non-CF and CF airway epithelia. Protein-level and transcript-level data indicate that temperature-sensitive changes in $\mathrm{ENaC}$ activity may be attributed to the downregulation of $\mathrm{ENaC}$ expression.

Low temperature incubation is a widely used experimental tool in vitro to enhance folding and trafficking of F508del-CFTR. ${ }^{810-1224-27}$ Fewer studies have sought to identify the impact of experimental temperature manipulation on other epithelial ion transport processes. In 
CF bronchial epithelial (CFBE) cells, low temperature incubation increased CFTR surface expression and channel activity, and resulted in lower activity of another $\mathrm{Cl}^{-}$channel, the outwardly rectifying $\mathrm{Cl}^{-}$channel. ${ }^{9}$ In the present investigation, low temperature incubation resulted in an expected increase in F508del-CFTR activity after incubation at $29^{\circ} \mathrm{C}$ compared with $37^{\circ} \mathrm{C}$, a decrease in $\mathrm{ENaC}$ activity and no effect on the ATP response, which is traditionally viewed as an indicator of CaCC activity. Thus, the impact of low temperature, which could affect many protein regulatory processes, such as protein synthesis, proteolytic activation or protein turnover, appears to be protein-specific rather than general. Importantly, the impact of low temperature incubation on $\mathrm{ENaC}$ activity was substantial and will be the primary topic of the discussion that follows.

In the $37^{\circ} \mathrm{C}$ controls for our study, $\mathrm{ENaC}$ activity was greater in $\mathrm{CF}$ than non-CF airway epithelia (figure 1D). The upregulation of $\mathrm{ENaC}$ activity in $\mathrm{CF}$ cultures is firmly established. ${ }^{13} 14$ 28-36 In both epithelial and non-epithelial cells, CFTR membrane expression and activity is negatively associated with $\mathrm{ENaC}$ expression or $\mathrm{ENaC}$-mediated $\mathrm{Na}^{+}$transport. ${ }^{1428-34}$ The reciprocal balance of the activities of ENaC and CFTR on the airway epithelium may aid in maintaining proper osmoregulation of periciliary fluid in non-CF epithelia, but likely exacerbates the dysregulation of ASL homeostasis caused by mutations in CFTR. ${ }^{35}$ When CFTR membrane expression on airway epithelia decreases due to improper folding and membranetrafficking (such as in the case of F508del-CFTR), ENaC functional expression is enhanced, ${ }^{36}$ leading to decreased ASL volume, thus worsening mucociliary clearance. ${ }^{13}$

The mechanism by which CFTR and ENaC interact is not well understood. Investigations into the CFTR interacting proteome (ie, the CFTR 'interactome') using co-immunoprecipitation (co-IP) of endogenously expressed CFTR did not find any interaction between ENaC and wild-type-CFTR or F508del-CFTR at $37^{\circ} \mathrm{C}$ or F508del-CFTR at $30^{\circ} \mathrm{C} .{ }^{37}{ }^{38}$ Conversely, studies using systems exogenously overexpressing CFTR and ENaC have shown a direct interaction between CFTR and ENaC $\alpha, \beta$ and $\gamma$ subunits in co-IP and fluorescence energy transfer (FRET) experiments. ${ }^{28} 3940$ Interestingly, low-temperature $\left(27^{\circ} \mathrm{C}\right)$ incubation is required for F508del-CFTR to exhibit direct interaction (co-IP) and physical proximity (FRET) with $\mathrm{ENaC},{ }^{39}$ indicating that the interaction between CFTR and ENaC likely takes place only once the proteins have trafficked to the plasma membrane. Neither incubation at $37^{\circ} \mathrm{C}$ nor $27^{\circ} \mathrm{C}$ resulted in any such interaction between $\mathrm{ENaC}$ and the $\mathrm{Cl}^{-}$channel CLC- $1,{ }^{39}$ although $\mathrm{ENaC}$ is known to interact with another CLC family member, CLC-2. ${ }^{41}$ From these previous studies, it appears that the functional relationship between CFTR and ENaC is likely occurring through direct and indirect mechanisms, which both require future investigation. It appears that CFTR can physically interact with $\mathrm{ENaC}$ on the plasma membrane to reduce $\mathrm{ENaC}$ function in cell lines exogenously expressing CFTR and $\mathrm{ENaC}$, and that the defective membrane-trafficking of F508del-CFTR prevents direct interaction with ENaC. However, the lack of detection of $\mathrm{ENaC}$ in the interactome of wild-type-CFTR or F508del-CFTR in cell lines endogenously expressing CFTR indicates that indirect functional interaction between CFTR and ENaC, facilitated through intermediary or accessory proteins, is likely a predominant mode of interaction between CFTR and $\mathrm{ENaC}^{283442}$

In the present study, low temperature incubation of F508del-CFTR monolayers resulted in increased CFTR activity and decreased $\mathrm{ENaC}$ activity (figure $3 \mathrm{~A}$ and $\mathrm{C}$ ). This finding agrees with the well-known effects of low temperature in modulating F508del-CFTR membrane presence ${ }^{7-9}$ A novel aspect of the present study is that we assessed the influence of low temperature in non-CF in addition to $\mathrm{CF}$ primary-derived epithelial cells. In CFBE410 cells, which exogenously express CFTR, low temperature $\left(29^{\circ} \mathrm{C}\right)$ incubation reduced wild-type-CFTR activity. ${ }^{25}$ In contrast, in the present study we found no change in CFTR activity in non-CF epithelia at $29^{\circ} \mathrm{C}$ (figure $3 \mathrm{C}$ ). The difference between the exogenous expression of CFTR in CFBE410 cells and the endogenous expression of CFTR in our primary-derived nasal epithelial cells may account for this difference in the CFTR-regulatory response at low temperature.

An important finding in the present study was that in both non-CF and CF epithelial cells, low temperature incubation reduced apparent $\mathrm{ENaC}$ activity (figure 3A). Furthermore, the reduction in ENaC activity substantially altered baseline transepithelial electrical properties such as membrane potential (figure 4A). The strong relationship between ENaC activity and baseline TEPD demonstrates the important influence of ENaC function on hydromineral balance on the airway epithelium. ENaC activity appeared to have a greater influence on baseline TEPD in CF than non-CF epithelia, which is likely due to lower CFTR activity in CF epithelia. Furthermore, in $\mathrm{CF}$ epithelia, the relationship between $\mathrm{ENaC}$ activity and baseline TEPD was similar regardless of temperature incubation (figure 4A). From these data, it appears that low temperature treatment affects ENaC function through a mechanism that is not necessarily dependent on CFTR, and that the reduced ENaC function at low temperature has a direct impact on baseline transepithelial membrane potential.

The cellular/molecular mechanisms responsible for the downregulation of $\mathrm{ENaC}$ activity at low temperature are not clear. Dysregulation of ENaC channel gating, membrane localization and surface residency time are all known pathologies for several human diseases. ${ }^{43}$ Along with reduced CFTR function, hyperactivity of ENaCmediated $\mathrm{Na}^{+}$absorption exacerbates mucous dehydration and worsens symptoms of $\mathrm{CF}^{44}$ Hyperactivation of $\mathrm{ENaC}$ as a contributing factor of $\mathrm{CF}$ lung disease specifically is thought to be the result of increased $\mathrm{ENaC}$ open probability $\left(P_{\mathrm{o}}\right)$ and/or increased ENaC surface expression. It has been shown in Xenopus oocytes that CFTR 
activation decreases the $\mathrm{ENaC} P$ without affecting its surface expression. ${ }^{45}$ Increased ENaC $P_{\mathrm{o}}$ can occur by proteolytic cleavage of an extracellular loop by various proteases. ${ }^{46}$ Increased ENaC surface expression can be regulated by cAMP/PKA inhibition of NEDD4-mediated ubiquitination and proteasomal degradation of ENaC. ${ }^{46}$

The extent to which altered $P_{\mathrm{o}}$ and/or surface expression is the cause of the reduced ENaC activity that we observed at $29^{\circ} \mathrm{C}$ is only partially answered in the present study. Direct comparisons of the results in the present study to the literature are difficult. Although many studies have used low temperature incubation to experimentally enhance F508del-CFTR, we could not identify any studies describing the effect of low temperature incubation on the ENaC activity. It was shown in CFBE410 cells that low temperature $\left(29^{\circ} \mathrm{C}\right)$ incubation increased TEER independently of CFTR membrane presence or activity, ${ }^{24}$ although the impact of low temperature incubation on ENaC expression or activity was not disclosed. In the present study, we similarly demonstrate an increase in TEER after low temperature incubation (figure 1C) and attribute this change primarily to a change in $\mathrm{ENaC}$ activity. Experimentally applied acute low temperature treatment has been shown to increase $\mathrm{ENaC} P_{\mathrm{o}}{ }^{47}{ }^{48}$ It is possible that prolonged exposure to low temperature (such as in the present study) results in sustained increases in $\mathrm{ENaC} P_{\mathrm{o}}$, thus eliciting a regulatory response by the cells to decrease ENaC activity.

Our RT-qPCR and western blot analyses demonstrated that transcript and/or protein expression of all three $\mathrm{ENaC}$ subunits $(\alpha, \beta$ and $\gamma$ ) were downregulated. As $\mathrm{ENaC}$ activity requires all three subunits to be present, the downregulation of any one of the $\mathrm{ENaC}$ subunits could explain the observed decreases in ENaC activity. Our results indicate differential regulation of ENaC subunits; transcription of $S C N N 1 B$ and $S C N N 1 G$ was strongly downregulated at low temperature whereas SCNN1A was not (figure 5A-C). Despite no observed reduction at the transcript level, protein expression of the $\mathrm{ENaC} \alpha$ subunit was still reduced (figure 5E). Given this finding, we surmise that protein expression of $\beta$ and $\gamma$ subunits, which were strongly downregulated at the transcript level, were likely reduced. Thus, our results indicate that it is possible that downregulation of $\mathrm{ENaC}$ transcript and protein synthesis at low temperature can fully explain the downregulation in $\mathrm{ENaC}$ activity. It is important to note that both microarray ${ }^{12}$ and proteomic ${ }^{27}$ analyses have revealed that many cellular functions are affected by low temperature incubation. Therefore, there could be other cellular mechanisms responding to low temperature incubation that may be affecting ENaC activity. Given that, in the present study, differences in the TEPD and Isc of non-CF epithelia were observed between $37^{\circ} \mathrm{C}$ and $29^{\circ} \mathrm{C}$ treatments after the addition of amiloride (figure 4C-E), we think it is likely that low temperature incubation affects other processes related to epithelial ion transport in addition to the downregulatory effect low temperature incubation has on ENaC activity.
In conclusion, we have reported that $\mathrm{ENaC}$ activity in primary-derived airway epithelia is substantially reduced after low temperature incubation. This effect of low temperature appears to be specifically acting on some ion transport mechanisms, namely F508del-CFTR and ENaC, but not others, such as CaCCs. Importantly, the reduction in $\mathrm{ENaC}$ activity and expression after low temperature incubation was observed in both non-CF and CF cultures indicating that this effect may occur through a CFTRindependent mechanism. Future studies seeking to use low temperature incubation to experimentally correct mutant CFTR should consider the impact low temperature incubation may have on other ion transporters as well as on epithelial function more broadly, including impacts on TEPD, ASL hydration and mucociliary transport. Lastly, for investigators interested in studying ENaC function, we speculate that low temperature incubation may be a useful experimental paradigm to induce specific downregulation of $\mathrm{ENaC}$ activity in order to study the $\mathrm{ENaC}$ dysfunction in various disease and model systems.

Acknowledgements The authors would like to thank Dr Robert Bridges, the Rosalind Franklin University of Medicine and the Cystic Fibrosis Foundation for the contribution of CFTRinh-172 through the CFTR Chemical Compound Distribution Programme.

Contributors SY, CAS and PEB conceived of and designed the research and performed experiments; SY, CAS and PEB analysed data and prepared the figures; SY and CAS produced the original manuscript draft; SY, CAS, PLZ and PEB revised and approved the final version of manuscript; PLZ and PEB facilitated the research.

Funding This research was supported by the Cystic Fibrosis Foundation (ZEITLI2010 to PLZ and BRATCH16I0 to PEB), the Eugene F. and Easton M. Crawford Charitable Lead Unitrust (to CAS and PEB), the Gilead Sciences Research Scholars Programme in Cystic Fibrosis (to PEB) and the Department of Paediatrics at National Jewish Health.

Competing interests None declared.

Patient and public involvement Patients and/or the public were not involved in the design, or conduct, or reporting, or dissemination plans of this research.

Patient consent for publication Not required.

Ethics approval This study was approved by the Institutional Review Board of National Jewish Health: HS-2832.

Provenance and peer review Not commissioned; externally peer reviewed.

Data availability statement All data relevant to the study are included in the article.

Open access This is an open access article distributed in accordance with the Creative Commons Attribution Non Commercial (CC BY-NC 4.0) license, which permits others to distribute, remix, adapt, build upon this work non-commercially, and license their derivative works on different terms, provided the original work is properly cited, appropriate credit is given, any changes made indicated, and the use is non-commercial. See: http://creativecommons.org/licenses/by-nc/4.0/.

\section{ORCID iD}

Preston E Bratcher http://orcid.org/0000-0003-2240-8632

\section{REFERENCES}

1 Boucher R. Regulation of airway surface liquid volume by human airway epithelia. Pflugers Arch - Eur J Physiol 2003;445:495-8.

2 Bartoszewski R, Matalon S, Collawn JF. Ion channels of the lung and their role in disease pathogenesis. Am J Physiol Lung Cell Mol Physiol 2017;313:L859-72.

3 Rowe SM, Miller S, Sorscher EJ. Cystic fibrosis. N Engl J Med 2005;352:1992-2001.

4 Kerem B, Rommens J, Buchanan J, et al. Identification of the cystic fibrosis gene: genetic analysis. Science 1989;245:1073-80. 
5 Cheng SH, Gregory RJ, Marshall J, et al. Defective intracellular transport and processing of CFTR is the molecular basis of most cystic fibrosis. Cell 1990;63:827-34.

6 Jensen TJ, Loo MA, Pind S, et al. Multiple proteolytic systems, including the proteasome, contribute to CFTR processing. Cell 1995;83:129-35.

7 Denning GM, Anderson MP, Amara JF, et al. Processing of mutant cystic fibrosis transmembrane conductance regulator is temperature-sensitive. Nature 1992;358:761-4.

8 Rennolds J, Boyaka PN, Bellis SL, et al. Low temperature induces the delivery of mature and immature CFTR to the plasma membrane. Biochem Biophys Res Commun 2008;366:1025-9.

9 Egan ME, Schwiebert EM, Guggino WB. Differential expression of ORCC and CFTR induced by low temperature in CF airway epithelial cells. Am J Physiol 1995;268:C243-51.

10 Farinha CM, King-Underwood J, Sousa M, et al. Revertants, low temperature, and correctors reveal the mechanism of F508del-CFTR rescue by VX-809 and suggest multiple agents for full correction. Chem Biol 2013;20:943-55.10.1016/j. chembiol.2013.06.004

11 Sondo E, Tomati V, Caci E, et al. Rescue of the mutant CFTR chloride channel by pharmacological correctors and low temperature analyzed by gene expression profiling. Am J Physiol Cell Physiol 2011;301:C872-85.

12 Zhang D, Ciciriello F, Anjos SM, et al. Ouabain mimics low temperature rescue of F508del-CFTR in cystic fibrosis epithelial cells. Front Pharmacol 2012;3:1-15.

13 Hobbs CA, Da Tan C, Tarran R. Does epithelial sodium channel hyperactivity contribute to cystic fibrosis lung disease? J Physiol 2013;591:4377-87.

14 Kunzelmann K, Schreiber R, Nitschke R, et al. Control of epithelial $\mathrm{Na}+$ conductance by the cystic fibrosis transmembrane conductance regulator. Pflugers Arch - Eur J Physiol 2000;440:193-201.

15 Berdiev BK, Qadri YJ, Benos DJ. Assessment of the CFTR and ENaC association. Mol Biosyst 2009;5:123-7.

16 Collawn JF, Lazrak A, Bebok Z, et al. The CFTR and ENaC debate: how important is $\mathrm{ENaC}$ in CF lung disease? Am J Physiol Lung Cell Mol Physiol 2012;302:L1141-6.

17 Zhou Z, Duerr J, Johannesson B, et al. The ENaC-overexpressing mouse as a model of cystic fibrosis lung disease. J Cyst Fibros 2011;10 Suppl 2:S172-82.

18 Bratcher PE, Yadav S, Shaughnessy CA, et al. Effect of apical chloride concentration on the measurement of responses to CFTR modulation in airway epithelia cultured from nasal brushings. Physiol Rep 2020;8:e14603.

19 Chioccioli M, Feriani L, Kotar J, et al. Phenotyping ciliary dynamics and coordination in response to CFTR-modulators in cystic fibrosis respiratory epithelial cells. Nat Commun 2019;10:1763.

20 Goldfarbmuren KC, Jackson ND, Sajuthi SP, et al. Dissecting the cellular specificity of smoking effects and reconstructing lineages in the human airway epithelium. Nat Commun 2020;11.

21 Reynolds SD, Rios C, Wesolowska-Andersen A, et al. Airway progenitor clone formation is enhanced by Y-27632-Dependent changes in the transcriptome. Am J Respir Cell Mol Biol 2016;55:323-36.

22 Kashlan OB, Kinlough CL, Myerburg MM, et al. N -linked glycans are required on epithelial $\mathrm{Na}^{+}$channel subunits for maturation and surface expression. Am J Physiol Renal Physiol 2018;314:F483-92.

23 Shabbir W, Tzotzos S, Bedak M, et al. Glycosylation-Dependent activation of epithelial sodium channel by solnatide. Biochem Pharmacol 2015;98:740-53.

24 LeSimple P, Liao J, Robert R, et al. Cystic fibrosis transmembrane conductance regulator trafficking modulates the barrier function of airway epithelial cell monolayers. J Physiol 2010;588:1195-209.

25 Froux L, Coraux C, Sage E, et al. Short-Term consequences of F508del-CFTR thermal instability on CFTR-dependent transepithelial currents in human airway epithelial cells. Sci Rep 2019;9:1-12.

26 Jurkuvenaite $A$, Chen L, Bartoszewski R, et al. Functional stability of rescued $\Delta \mathrm{F} 508$ cystic fibrosis transmembrane conductance regulator in airway epithelial cells. Am J Respir Cell Mol Biol 2010;42:363-72.
27 Gomes-Alves P, Neves S, Coelho AV, et al. Low temperature restoring effect on F508del-CFTR misprocessing: a proteomic approach. J Proteomics 2009;73:218-30.

28 Gentzsch M, Dang H, Dang Y. The cystic fibrosis transmembrane conductance regulator impedes proteolytic stimulation of the epithelial $\mathrm{Na}+$ channel. Journal of Biological Chemistry 2010;285:32227-32.

29 Ismailov II, Awayda MS, Jovov B, et al. Regulation of epithelial sodium channels by the cystic fibrosis transmembrane conductance regulator. Journal of Biological Chemistry 1996;271:4725-32.

30 König J, Schreiber R, Voelcker T, et al. The cystic fibrosis transmembrane conductance regulator (CFTR) inhibits ENaC through an increase in the intracellular $\mathrm{Cl}^{-}$concentration. $E M B O$ Rep 2001:2:1047-51.

31 Mall M, Bleich M, Greger R, et al. The amiloride-inhibitable Na+ conductance is reduced by the cystic fibrosis transmembrane conductance regulator in normal but not in cystic fibrosis airways. $J$ Clin Invest 1998;102:15-21.

32 Mall M, Bleich M, Kuehr J, et al. CFTR-mediated inhibition of epithelial $\mathrm{Na}^{+}$conductance in human colon is defective in cystic fibrosis. Am J Physiol Gastrointest Liver Physiol 1999;277:G709-16.

33 Yan W, Samaha FF, Ramkumar M, et al. Cystic fibrosis transmembrane conductance regulator differentially regulates human and mouse epithelial sodium channels in Xenopus oocytes. $J$ Biol Chem 2004:279:23183-92.

34 Stutts M, Canessa C, Olsen J, et al. Cftr as a cAMP-dependent regulator of sodium channels. Science 1995;269:847-50.

35 Matsui $\mathrm{H}$, Grubb BR, Tarran R, et al. Evidence for periciliary liquid layer depletion, not abnormal ion composition, in the pathogenesis of cystic fibrosis airways disease. Cell 1998:95:1005-15.

36 Rubenstein RC, Lockwood SR, Lide E, et al. Regulation of endogenous ENaC functional expression by CFTR and $\triangle F 508$ CFTR in airway epithelial cells. Am J Physiol Lung Cell Mol Physiol 2011;300:L88-101.

37 Wang X, Venable J, LaPointe P, et al. Hsp90 cochaperone Aha1 downregulation rescues misfolding of CFTR in cystic fibrosis. Cell 2006;127:803-15.

38 Pankow S, Bamberger C, Calzolari D, et al. $\triangle$ F508 CFTR interactome remodelling promotes rescue of cystic fibrosis. Nature 2015;528:510-6.

39 Qadri YJ, Cormet-Boyaka E, Rooj AK, et al. Low temperature and chemical rescue affect molecular proximity of $\Delta \mathrm{F} 508$-cystic fibrosis transmembrane conductance regulator (CFTR) and epithelial sodium channel (ENaC). Journal of Biological Chemistry 2012;287:16781-90.

40 Berdiev BK, Cormet-Boyaka E, Tousson A, et al. Molecular proximity of cystic fibrosis transmembrane conductance regulator and epithelial sodium channel assessed by fluorescence resonance energy transfer. J Biol Chem 2007;282:36481-8.

41 Henry KR, Lee S, Walker D, et al. Direct interactions between ENaC gamma subunit and CLCN2 in cystic fibrosis epithelial cells. Physiol Rep 2015;3:e12264-10.

42 Stutts MJ, Rossier BC, Boucher RC. Cystic fibrosis transmembrane conductance regulator inverts protein kinase A-mediated regulation of epithelial sodium channel single channel kinetics. J Biol Chem 1997;272:14037-40.

43 Butterworth MB. Regulation of the epithelial sodium channel (ENaC) by membrane trafficking. Biochim Biophys Acta 2010;1802:1166-77.

44 Tarran R, Grubb BR, Parsons D, et al. The CF salt controversy: in vivo observations and therapeutic approaches. Mol Cell 2001;8:149-58.

45 Konstas A-A, Koch J-P, Korbmacher C. cAMP-Dependent activation of CFTR inhibits the epithelial sodium channel (ENaC) without affecting its surface expression. Pflugers Arch - Eur J Physiol 2003;445:513-21.

46 Moore PJ, Tarran R. The epithelial sodium channel (ENaC) as a therapeutic target for cystic fibrosis lung disease. Expert Opin Ther Targets 2018;22:687-701.

47 Askwith CC, Benson CJ, Welsh MJ, et al. Deg/Enac ion channels involved in sensory transduction are modulated by cold temperature. Proc Natl Acad Sci U S A 2001;98:6459-63.

48 Chraïbi A, Horisberger J-D. Dual effect of temperature on the human epithelial Na+ channel. Pflugers Arch 2003;447:316-20. 